University of Windsor

Scholarship at UWindsor

$10-2-2017$

\title{
Higher colonization pressure increases the risk of sustaining invasion by invasive non-indigenous species
}

Hugh J. Maclssaac

University of Windsor

Mattias L. Johansson

Follow this and additional works at: https://scholar.uwindsor.ca/biologypub

Part of the Biology Commons

\section{Recommended Citation}

Maclssaac, Hugh J. and Johansson, Mattias L., "Higher colonization pressure increases the risk of sustaining invasion by invasive non-indigenous species" (2017). Aquatic Ecosystem Health \& Management, 20, 4, 378-383.

https://scholar.uwindsor.ca/biologypub/1213

This Article is brought to you for free and open access by the Department of Biological Sciences at Scholarship at UWindsor. It has been accepted for inclusion in Biological Sciences Publications by an authorized administrator of Scholarship at UWindsor. For more information, please contact scholarship@uwindsor.ca. 
1

2

3

4

5

6

7

8

9

10

11

12

13

14

15

$16 \quad{ }^{1}$ Correspondence: hughm@uwindsor.ca, ph (519) 253-3000 x 3754

17

18

Higher colonization pressure increases the risk of sustaining invasion by invasive non-indigenous species

Hugh J. Maclsaac ${ }^{1}$ and Mattias L. Johansson

Great Lakes Institute for Environmental Research

University of Windsor

Windsor, Ontario, Canada N9B 3P4

4

5 


\section{Abstract}

Considerable attention has been focused on the concept of Propagule Pressure (PP; number of individuals introduced and introduction events) as a predictor of invasion success (975 papers). Much less well studied is the role of Colonization Pressure (CP; number of species introduced; 24 studies), the complement of PP. Here we review the invasion history of the Laurentian Great Lakes to predict the risk of a future invasive (i.e. producing adverse ecological effects on other species) non-indigenous species (NIS) based upon the number of species introduced (CP), using the recorded history of invasions in this system as our starting point. Historically, $52 \%$ of the fishes that were introduced and became established in the Great Lakes were subsequently identified in the literature as invasive, whereas the value for invertebrates (16\%) was much lower. Assuming future invaders have similar invasion attributes as those already present, the risk of getting at least one high impact species is positively and asymptotically related to the number of species introduced, though the rate is substantially higher for fishes than for invertebrates. Our study provides support for the contention that managers ought to focus initially on vectors transmitting multiple species when attempting to prevent invasion of their system by species likely to become problematic.

Keywords: Colonization pressure, propagule pressure, invasion success, invasive species, Great Lakes 


\section{Introduction}

Ecologists have taken many different approaches to predict which species will become invasive (i.e. problematic) when introduced to new systems and which ecosystems are most vulnerable to invasion. Approaches for the former include consideration of native range area, life history characteristics, history of invasiveness, and the nature of biological interactions, while those for the latter include climate matching, degree of human disturbance or habitat insularity, and resource availability, among others (see Elton, 1958; Williamson and Fitter, 1996; Colautti et al., 2006; Lodge et al., 2006; Richardson and Pyšek, 2006; Hayes and Barry, 2008; Lonsdale, 2009; Jeschke et al., 2012). Simberloff (2009) attributes Mark Williamson (1996) with introducing the concept of Propagule Pressure to predict species invasiveness (also see Williamson and Fitter, 1996a,b). Propagule Pressure includes multiple components, the main ones being the number of individuals introduced and the number of introduction events (Lockwood et al., 2005; Simberloff, 2009). Propagule Pressure is important because as more individuals are introduced, the likelihood of overcoming demographic constraints - like Allee effects - also increases (Lockwood et al., 2005). The number of introduction events is important since it may allow demographic rescue of previously introduced individuals, as well as providing multiple opportunities to colonize in the face of environmental stochasticity in the receiving habitat (Lockwood et al., 2005; Simberloff, 2009). Propagule Pressure also includes the condition of propagules introduced, and the abundance of the invader in its native range from which propagules are entrained in an invasion vector. The latter variable is potentially important since - all 
63 things being equal - higher abundance in the native region provides a potentially larger

64 inoculum when entrained in the invasion vector (Blackburn et al., 2015).

Colonization Pressure - the number of species introduced - is a critical

66 parameter for predicting invasion of habitats. The concept is grounded in the view that

67 each species has a different invasion potential when introduced into a particular habitat,

68 and as the number of species introduced increases so, too, does the likelihood that at

69 least one species will have its establishment requirements met (Lockwood et al., 2009).

70 Colonization Pressure has been explored with birds and waterstriders, and using

71 simulated and real ballast water communities (Ahlroth et al., 2003; Chiron et al., 2009;

72 Lockwood et al., 2009; Briski et al., 2013; Chan et al., 2015a). Lockwood et al. (2009)

73 demonstrated as the total inoculum introduced to a habitat increases, both Propagule

74 Pressure and Colonization Pressure increase, with the latter asymptoting as rare

75 species are slowly added while the former continues to increase.

One concern with increased Colonization Pressure is the increased risk of

77 entraining an invasive NIS (Ricciardi and Kipp, 2008; Ricciardi and Maclsaac, 2011).

78 This problem is, in fact, a variant of the Propagule Pressure concept. If risk of invasion

79 by a highly invasive NIS does, in fact, increase with Colonization Pressure, then it would

80 follow that management ought to focus efforts on vectors capable of transmitting

81 multiple species before those capable of introducing only single species. In this study,

82 we explore this issue using the invasion histories of the Laurentian Great Lakes with respect to successfully established fishes and invertebrates.

85 Methods 
We assessed the relative prominence of the terms "propagule pressure" and "colonization pressure" in the ecological literature between 2000 and 2016 (September $9,2016)$ using either of the terms combined with "biological invasion" or "species invasion" or "invasive species" or "nonindigenous species" in Web of Science. Two metrics were arbitrarily selected to determine popularity of papers using these terms as keywords: total number of papers, and number of papers citing the terms.

To estimate the probability of introducing at least one high-impact invader species to a new area, we performed a probability analysis using the hypergeometric distribution (phyper function in R; R Core Team, 2016). We based the proportion of high-impact versus no-reported impact invaders for this analysis on fish and invertebrate species already introduced - by any vector - and established in the Laurentian Great Lakes (GLANSIS, 2016). All fish and invertebrate species were reviewed for demonstrated 'impact' in the Great Lakes based on Web of Scienceretrieved publications. This analysis is likely conservative as only reports that explicitly identified adverse ecological effects (i.e. predation, competition, parasitism) involving native species in the Great Lakes were considered as having an impact. Furthermore, if a species has, for example, a parasitic life history but available reports failed to identify any adversely-affected species in the Great Lakes, we did not apply the 'invasive' tag to that species. Analyses were conducted separately for invertebrates and fishes. Using the proportion of high-impact invaders from the Great Lakes, we calculated the probability of introducing least one high-impact fish or invertebrate invader when introducing from one to ten total species to a new area. Specifically, we modeled the likelihood of getting at least one high impact invader $[P(X \geq 1)]$ as: 


$$
\mathrm{P}(\mathrm{X} \geq 1)=\sum_{k=1}^{n} \frac{\left(\begin{array}{l}
K \\
k
\end{array}\right)\left(\begin{array}{l}
N-K \\
n-k
\end{array}\right)}{\left(\begin{array}{l}
N \\
n
\end{array}\right)}
$$

\section{Results and Discussion}

\section{Results and Discussion}

where $\mathrm{N}$ is the total pool of invaders, $\mathrm{K}$ is the number of high-impact invaders, $\mathrm{n}$ is the number of species introduced, and $\mathrm{k}$ is the number of high-impact invaders drawn.

Thus, our model calculated the total probability of drawing one or more high-impact invaders for each step from one to ten species introduced to a new area. Our analysis assumes that introduced species subsequently establish, though, in reality, each species will have a separate probability associated with this stage of invasion. While Propagule Pressure and Colonization Pressure are both utilized in the invasion literature, they are not equally represented. There have been 975 versus 24 publications, respectively, that utilized these terms since 1996. Propagule Pressure was used earlier than Colonization Pressure - which was previously simply called number of species introduced - and it remains more popular today (120 versus 6 publications, respectively, in 2015). Propagule Pressure is also cited much more commonly than Colonization Pressure, with 4846 and 46 citations in 2015, respectively. Both Propagule Pressure and Colonization Pressure have multiple components, including abundance of individuals/species in the source pool, number of individuals/species entrained and released by a vector, and the number of introduced individual/species that establish (Simberloff, 2009; Lockwood and Blackburn, 2009; Blackburn et al., 2015). Propagule Pressure also considers the number of introduction events. Part of the difference in popularity of studies using the two terms may relate to the fact that the 
131 number of individuals introduced has strong implications in evolutionary ecology via

132 founder effects and/or genetic drift (e.g. Bock et al., 2015).

There exists a positive but asymptotic relationship between the risk of at least one high-impact species invading successfully and the number of species introduced to a system (Fig. 1). There was a strong difference between risk associated with fish (13 of $25 ; 52 \%)$ versus invertebrate $(7$ of $45 ; 16 \%)$ invasions (Table 1$)$. This difference may be

137 attributable to the respective trophic levels of these taxa, body mass differences,

138 introduction mode (intentional in the case of most fishes versus accidental for most 139 invertebrates), research effort and consequent understanding of impacts, or a 140 combination of these factors. Our assessment of impactful fishes (52\%) corresponds 141 very closely with that of Mills et al. (1994), who reported that $50 \%$ of nonindigenous fish 142 species were high impact. Two of four fish species associated with ballast water 143 introduction were high impact. Twenty of the invertebrate species entered via ballast 144 water. ecologists than Propagule Pressure, it is nevertheless critically important to invasion 147 patterns (e.g. Chiron et al., 2009). For example, managers are often charged with 148 preventing biological invasions, and are given finite resources with which to conduct 149 their programs. A logical question thus arises as to how best to deploy the budget to 150 maximize social benefit? Our analysis - based upon the history of NIS that established 151 in the Great Lakes - suggests that the focus ought to be based on vectors capable of 152 introducing multiple species simultaneously. Multiple introduction increase the likelihood 153 of getting at least one high-impact species (Ricciardi and Kipp, 2008; Ricciardi et al., 
2011), the effect being more pronounced for fishes than invertebrates (Fig. 1). Ricciardi and Maclsaac (2011) previously observed that risk of sustaining invasion by an invasive NIS increased with number of species introduced across a spectrum of both freshwater and marine ecosystems, with the former seemingly being more vulnerable.

An obvious multiple-species vector is ballast water; however, since implementation of mandatory ballast water flushing rules by both the USA and Canada, there has not been a newly recorded ballast-mediated species introduction in the Great Lakes (Bailey et al., 2011). A second possibility is fouling organisms on exterior surfaces of vessels. While some species may have entered the Great Lakes via the mechanism (Mills et al., 1993), it is nowhere near as strong a vector as it is in marine systems where it can be the single-most important introduction mechanism. Other possible vectors might include the live trade in pond and aquarium species (Pugnacco et al., 2015), in which introduced aquatic plants could be fouled by nonindigenous invertebrates or algae, while introduced fishes or invertebrates may be parasitized by taxa non-indigenous to the system. For example, of 98 cases of co-introduction of species, more than $50 \%$ involved freshwater fishes and their parasites (Lymbery et al., 2014). Bait fish releases pose a further risk if the species sample is contaminated with by-catch species (Drake and Mandrak, 2014). In each of these cases, however, the total number of non-indigenous species introduced with a single introduction event is likely to pale in comparison to that associated with ballast water and hull fouling in marine environments (e.g. Chan et al., 2015b).

There may be exceptions to the concept of addressing multiple-species vectors first. If, for example, a highly invasive species is not yet present, and if it were likely to 
177 survive and disrupt the receiving ecosystem, a case could be made that a speciesspecific prevention program was warranted. For example, the Golden Mussel

Limnoperna fortunei, a native of East Asia, has spread widely in that region and through much of central South America. The species is ecologically similar to the Zebra Mussel Dreissena polymorpha, though it seemingly has broader ecological tolerances and would pose an even greater ecological risk (Ricciardi, 1998). In both Asia and South America, the species is associated with severe biofouling of industrial and municipal water intakes and strong ecological effects. It is not present in North America, Europe or Australia, and prevention measures to ensure it is not introduced would be prudent. Likewise, concern about Bighead Carp (Hypophthalmichthys nobilis) and Silver Carp $(H$.

187 molitrix) entering the Great Lakes has preoccupied managers throughout the Great Lakes region, resulting in proposals to reengineer Chicago Area Waterways at great expense to prevent invasion of Lake Michigan (USACE, 2014). Despite these specific case studies where preventing invasion by one or a few species appears justified, in general it would appear that preventative measures that target multi-species vectors would be both more cost-effective and cost-efficient at preventing invasive NIS from entering new ecosystems.

It is surprising that thus far only a handful of studies have explicitly assessed the importance of Colonization Pressure in risk assessments of sustaining a future invasion by one or more invasive NIS (Ahlroth et al., 2003; Verling et al., 2005; Roman and Darling, 2007; Ricciardi and Kipp, 2008; Chiron et al., 2009; Ricciardi and Maclsaac, 2011). This dearth of studies may be because researchers are more familiar with 199 Propagule Pressure and its constituent parts, or because they work on individual 
200 species or on vectors that transmit only one or a few species. Results from this and

201 previous studies indicate, however, that Colonization Pressure is also important and 202 ought not to be ignored.

\section{Acknowledgements}

205 HJM would like to thank Drs. Mohi Munawar, Sarah Bailey, and Francisco Sylvester for 206 the opportunity to speak at the Marine and Freshwater Invasive Species conference 207 held in Buenos Aires, Argentina. We are grateful for reviewer comments and for 208 financial support from a NSERC Discovery grant and Canada Research Chair to HJM. 209

\section{References}

211 Ahlroth, P., Alatalo, R.V., Holopainen, A., Kumpulainen, T., Suhonen, J., 2003. Founder population size and number of source populations enhance colonization success in waterstriders. Oecologia 137, $617-620$.

Bailey, S.A., Deneau, M.G., Jean, L., Wiley, C.J., Leung, B., Maclsaac, H.J., 2011. Evaluating efficacy of an environmental policy to prevent biological invasions.

Blackburn, T.M., Essl, F., Evans, T., Hulme, P.H., Jeschke, J.M., Kühn, I., Kumschick, S., Marková, A., Mrugala, A., Nentwig, W., Pergl, J., Pyšek, P., Rabitsch, W., Ricciardi, A., Richardson, D.M., Sendek, A., Vilà, M., Wilson, J.R.U., Winter, M., Genovesi, P., Bacher, S., 2014. A unified classification of alien species based on the magnitude of their environmental impacts. PLoS One 12:e1001850 
222 Blackburn, T.M., Lockwood, J.L., Cassey, P., 2015. The influence of numbers on invasion success. Mol. Ecol. 24, 1942-1953.

224

225

226

227

228

229

230

231

232

233

234

235

236

237

238

239

240

241

242

243

Bock, D., Caseys, C., Cousens, R.D., Hahn, M.A., Heredia, S.M., Hubner, S., Turner, K.G., Whitney, K.D., Rieseberg, L.H., 2015. What we still do not know about invasion genetics. Mol Ecol. 24, 2277-2297.

Briski, E., Bailey, S.A., Casas-Monroy, O., DiBacco, C. , Kaczmarska, I., Levings, C., MacGillivary, M.L., McKindsey, C.W., Nasmith, L.E., Parenteau, M., Piercey, G.E., Rochon, A., Roy, S., Simard, N., Villac, M.C., Weise, A.M., Maclsaac, H.J., 2012. Relationship between propagule pressure and colonization pressure in invasion ecology: a test with ships' ballast. Proc Roy Soc B 279, 2990-2997.

Briski, E., Drake, D.A.R., Chan, F.T., Bailey, S.A., Maclsaac, H.J., 2013. Variation in propagule and colonization pressures following rapid human-mediated transport: Implications for a universal assemblage-based management model. Limnol. Oceanogr. 59, 2068-2076.

Chan, F.T., Bradie, J., Briski, E., Bailey, S.A., Simard, N., Maclsaac, H.J., 2015a. Assessing introduction risk using species' rank-abundance distributions. Proc. Roy. Soc. B 282, 20141517. doi:10.1098/rspb.2014.1517

Chan, F.T., Maclsaac, H.J., Bailey, S.A., 2015b. Relative importance of vessel hull fouling and ballast water as transport vectors of nonindigenous species to the Canadian Arctic. Can. J. Fish. Aquat. Sci. 72, 1230-1242.

Chiron, F., Shirley, S., Kark, S., 2009. Human-related processes drive the richness of exotic birds in Europe. Proc. Roy. Soc. B 276, 47-53. 
244 Colautti, R.I., Grigorovich, I.A., Maclsaac, H.J., 2006. Propagule pressure: a null model for biological invasions. Biol. Invas. 8, 1023-1037.

Drake, D.A.R., Mandrak, N.E., 2014. Ecological risk of live bait fisheries: A new angle on selective fishing. Fisheries 39, 201-211.

Drake, D.A.R., Chan, F.T., Briski, E., Bailey, S.A., Maclsaac, H.J., 2014. Assemblage structure: an overlooked component of human-mediated species movements among freshwater ecosystems. J. Limnol. 73, 112-9.

Elton, C.S. 1958. The Ecology of Invasions by Animals and Plants. Methuen, London. Great Lakes Aquatic Nonindigenous Species Information System (GLANSIS). 2016. NOAA Great Lakes Aquatic Nonindigenous Species Information System. Accessed 20 March 2016. http://www.glerl.noaa.gov/res/Programs/glansis/glansis.html Hayes, K.R., Barry S.C., 2008. Are there any consistent predictors of invasion success? Biol. Invas. 10, 483-506.

Jeschke, J.H., Haider, S., Lortie, C.J., Pyšek, P. Strayer, D.L., 2012. Support for major hypotheses in invasion biology is uneven and declining. Neobiota 14, 1-20.

Lockwood, J.L., Cassey, P., Blackburn, T.M., 2005. The role of propagule pressure in explaining species invasions. Trends Ecol. Evol. 20, 223-228.

Lockwood, J.L., Cassey, P., Blackburn, T.M., 2009. The more you introduce the more you get: the role of colonization pressure and propagule pressure in invasion ecology. Divers. Distrib. 15, 904-910.

Lodge, D.M., Williams, S., Maclsaac, H.J., Hayes, K.R., Leung, B., Reichard, S., Mack, R.N., Moyle, P.B., Smith, M., Andow, D.A., Carlton, J.T., McMichael, A., 2006. 
Biological invasions: recommendations for US policy and management. Ecol. Applic. 16, 2035-2054.

Lonsdale, W.M., 1999. Global patterns of plant invasions and the concept of invasibility. Ecology 80, 1522-1536.

Lymbery, A.J., Morine, M., Kanani, H.G., Beatty, S.J., Morgan, D.L., 2014. Co-invaders: The effects of alien parasites on native hosts. Int. J.Parasit.: Parasit. Wildlife 3, 171-177.

Mills, E.L., Leach, J.H., Carlton, J.T., Secor C.L.., 1993. Exotic species in the Great Lakes: a history of biotic crises and anthropogenic introductions. J. Great Lakes Res. 19, 1-54.

Mills, E.L., Leach, J.H., Carlton, J.T., Secor C.L.., 1994. Exotic species and the integrity of the Great Lakes. BioScience 44:666-676.

Pugnacco, K.S., Maynard, G.A., Fera, S.A., Yan, N.D., Nalepa, T.F., Ricciardi A., 2015. The future of species invasions in the Great Lakes-St. Lawrence River basin. J. Great Lakes Res. 41 (Supplement 1), 96-107.

Ricciardi, A., 1998. Global range expansion of the Asian mussel Limnoperna fortunei (Mytilidae): another fouling threat to freshwater systems. Biofouling 13, 97-106.

Ricciardi, A., Kipp, R., 2008. Predicting the number of ecologically harmful exotic species in an aquatic system. Divers. Distrib. 14, 374-380.

Ricciardi, A., Maclsaac, H.J., 2011. Impacts of biological invasions on freshwater ecosystems. Pp. 211-224 In: Fifty Years of Invasion Ecology: The Legacy of Charles Elton (D.M. Richardson, ed.), Wiley-Blackwell. 
288 Ricciardi, A., Jones, L., Kestrup, Á.M., Ward, J.M., 2011. Expanding the propagule

pressure concept to understand the impact of biological invasions. Pp. 225-235 In: Fifty Years of Invasion Ecology: The Legacy of Charles Elton (D.M. Richardson, ed.), Wiley-Blackwell.

Richardson, D.M., Pyšek, P., 2006. Plant invasions: merging the concepts of species invasiveness and community invasibility. Prog. Phys. Geog. 30, 409-431.

Roman, J., Darling, J.A., 2007. Paradox lost: genetic diversity and the success of aquatic invasions. Trends Ecol. Evol. 22, $454-464$.

Simberloff, D., 2009. The role of propagule pressure in biological invasions. Ann. Rev. Ecol. Evol. System. 40, 81-102.

United States Army Corps of Engineers (USACE). 2014. The Great Lakes and Mississippi River Interbasin Study (GLMRIS) Report. Available online at http://glmris.anl.gov/documents/docs/glmrisreport/GLMRIS_Report.pdf.

Verling, E., Ruiz, G.M., Smith, L.D., Galil, B., Miller, A.W., Murphy, K.R., 2005. Supply side invasion ecology: characterizing propagule pressure in coastal ecosystems. Proc. Roy. Soc. B 272, 1249 - 1257.

Williamson, M., 1996. Biological Invasions. London: Chapman and Hall.

Williamson, M., Fitter, A., 1996a. The characters of successful invaders. Biol. Conserv. 78, 163-170.

Williamson, M., Fitter, A., 1996b. The varying success of invaders. Ecology 77, 16611666. 
310 Table 1. Nonindigenous fishes and invertebrates in the Great Lakes (based on Great

311 Lakes Aquatic Nonindigenous Species Information System) that are invasive in the

312 system.

\begin{tabular}{|l|l|l|}
\hline Taxon & Scientific Name & Common Name \\
\hline Fishes & Alosa pseudoharengus & Alewife \\
\hline & Cyprinus carpio & Common Carp \\
\hline & Gymnocephalus cernua & Ruffe \\
\hline & Neogobius melanostomus & Round Goby \\
\hline & Petromyzon marinus & Sea Lamprey \\
\hline & Salmo trutta & Brown Trout \\
\hline & Oncorhynchus mykiss & Rainbow Trout \\
\hline & Oncorhynchus tshawytscha & Chinook Salmon \\
\hline & Oncorhynchus kisutch & Coho Salmon \\
\hline & Oncorhynchus gorbuscha & Pink Salmon \\
\hline & Morone americana & White Perch \\
\hline & Lepomis microlophus & Redear Sunfish \\
\hline & Scardinius erythrophthalmus & Rudd \\
\hline & Dreissena polymorpha & Zebra Mussel \\
\hline & Dreissena rostriformis bugenisis & Quagga Mussel \\
\hline & Bythotrephes longimanus & Spiny Waterflea \\
\hline & Cercopagis pengoi & Fishook Waterflea \\
\hline & Cordylophora caspia & Freshwater Hydroid \\
\hline & & \\
\hline & & \\
\hline & & \\
\hline & & \\
\hline & &
\end{tabular}


314 Figure 1. Probability of getting at least one new 'invasive' NIS as a function of number of

315

316

317 species introduced based upon prior introduction experiences in the Laurentian Great Lakes.

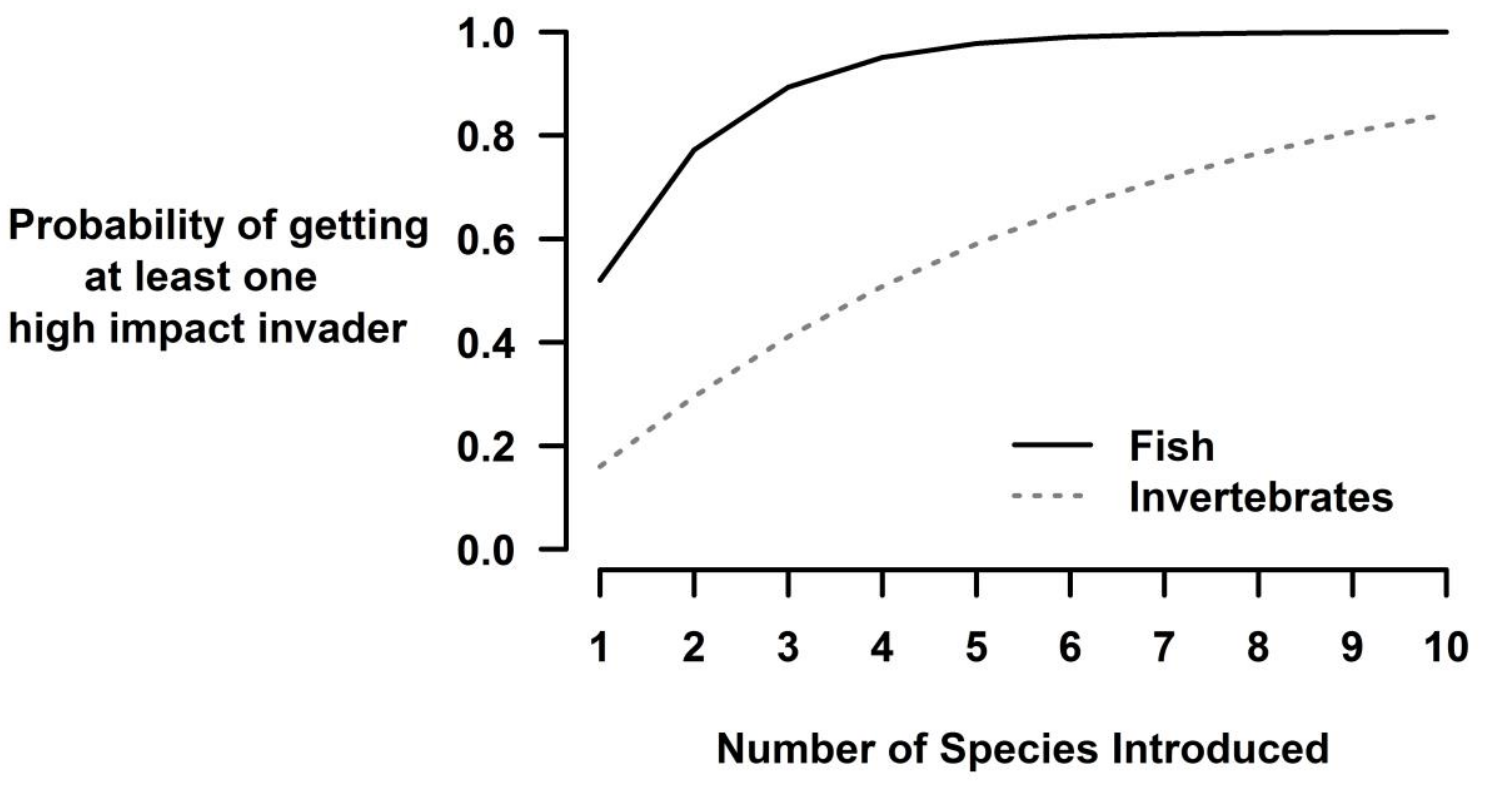

